\title{
DISCAPACIDAD
}

\section{Prácticas en el Centro Pedralbes: musicoterapia en educación especial}

\author{
Gabriela Mariana Costantini Avalos ${ }^{1}$
}

\begin{abstract}
Resumen
Introducción: El presente trabajo es el resumen de las prácticas de musicoterapia realizadas en el Centro Pedralbes en la Escola de Educación Especial los días lunes de 9 a 10 de la mañana en la ciudad de Barcelona que se desarrollaron desde noviembre de 2017 y finalizaron en mayo del 2018. Se trabajó con un grupo de preadolescentes de entre 12 y 15 de edad cronológica, tres mujeres y un varón. Una de las mujeres y el varón está diagnosticada con TEA, otra de las chicas con Síndrome de Angelman y la última con Síndrome de Rett.

Las prácticas consistieron en cuatro fases: observación, establecimiento de empatía, propuestas de intervención y evaluación. En el transcurso de las sesiones, se utilizaron intervenciones basadas en el enfoque de musicoterapia creativa de Nordoff-Robbins que enfatiza en la improvisación musical para promover y desarrollar el potencial del ser de la persona y el Método OrffSchulwerk que tiene como principio fundamental acercar la música a la persona mediante la tradición oral, los instrumentos de percusión y la prosodia. Las técnicas consistieron en improvisación musical con instrumentos de percusión, viento, madera y metalófonos. Asimismo, se utilizó la danza libre y la escucha de canciones grabadas o interpretadas por la terapeuta para momentos de activación rítmica y relajación.
\end{abstract}

Objetivos: Generar interacción y relación entre los miembros del grupo. Potenciar el desarrollo de las habilidades cognitivas-perceptivas. Estimular las habilidades psicomotrices fina y gruesa. Incentivar el uso de la comunicación no verbal y la expresión verbal. Motivar la expresión emocional.

Material y Método: Se contó con una variedad de objetos para trabajar todas las áreas de desarrollo y de instrumentos de cuerda, percusión y viento.

Las sesiones se realizaron una hora a la semana en la "Sala Multisensorial". Para evaluar el progreso de los niños se aplicó una hoja de seguimiento que medía la frecuencia de las conductas esperadas en el área emocional, cognitiva, motora, musical y conductual. Esta evaluación se realizaba cada mes para registrar el proceso de tratamiento musicoterapéutico.

1. Instituto de Formación Continua (IL3)-Universitat de Barcelona.

Esta investigación es un trabajo Final de Máster en Musicoterapia donde se realiza una memoria de prácticas del último año de master desde noviembre del 2017 a mayo del 2018.

E-mail: gabi.costantini@gmail.com

DOI: 10.26885/rcei.foro.2018.36 


\section{Prácticas en el Centro Pedralbes. Costantini Avalos}

Resultados: En general, se observó un cambio significativo en los cuatro sujetos. Se registró el aumento de las conductas esperadas en todas las áreas de desarrollo de manera gradual en los meses de marzo, abril, mayo.

Conclusiones: La musicoterapia tiene mucho que brindar a la educación especial por el efecto claro y directo de la música en los niños con discapacidades. Se evidenció la influencia de las experiencias musicales como la improvisación musical con instrumentos de todo tipo dejando un tiempo para que los niños los exploren y jueguen con ellos a su manera para luego compartir sonidos con los demás. Así también el valor del espacio para las vocalizaciones improvisadas donde se hacían juegos de palabras con los nombres o las acciones deseadas para generar el vínculo con el niño. Además, la importancia de combinar la música con el movimiento libre y la danza para una mejor experiencia utilizando canciones de sus preferencias musicales personales y de la etapa de desarrollo en la que se encuentran los sujetos.

Palabras clave: musicoterapia, educación especial, autismo.

\section{Referencias}

Bruscia, K. (2010). Modelos de improvisación en musicoterapia. Vitoria-Gateiz: Agruparte.

Lacárcel Moreno, J. (1995). Musicoterapia en Educación Especial. Murcia: Compobell, S.L

Mercadal-Brotons, M., Martí, P. (2012). Música, Musicoterapia y Discapacidad. Badalona: JIMS, S.L.

Orff, C. (1969). Orff-Schulwerk, música para niños. España: Unión Musical Española.

Willimans, C. Peters, S. y Caculator, S. (2009). Facts about Angelman Syndrome. Illinois: Angelman Syndrome Foundation. Inc. 